\title{
Examining life-course influences on chronic disease: the Ribeirão Preto and São Luís birth cohort studies (Brazil)
}

G.D. Batty

\author{
Correspondence \\ G.D. Batty \\ MRC Social and Public Health \\ Sciences Unit \\ 4 Lilybank Gardens \\ Glasgow \\ UK, G12 8RZ \\ Fax: +44-141-337-2389 \\ E-mail: david-b@msoc.mrc.gla.ac.uk
}

David Batty is a Wellcome

Trust fellow.

$\ldots \ldots \ldots \ldots \ldots \ldots \ldots$

Received August 21, 2007 Accepted August 21, 2007
MRC Social and Public Health Sciences Unit, University of Glasgow,

Glasgow, UK

\begin{abstract}
More than any other low- and middle-income country, Brazil has the longest research tradition of establishing, maintaining and exploiting birth cohort studies. This research pedigree is highlighted in the present issue of the Brazilian Journal of Medical and Biological Research, which contains a series of twelve papers from the Ribeirão Preto and São Luis birth cohort studies from the Southeast and Northeast of Brazil, respectively. The topics covered in this raft of reports vary and include predictors of perinatal health and maternal risk factors, early life determinants of cardiovascular risk factors in childhood and adolescence, use of health services, and a description of dietary characteristics of young adults, amongst other topics. There is also a guide to the background, objectives, sampling and protocols employed across these studies, which, together with similar pieces published in past issues of the Brazilian Journal, serve as a very useful starting point, particularly for potential collaborators. In the fervent hope that further follow-up of these cohorts will take place - we provide our own justification for cohort maintenance and extension in this issue - future data collection could include: genetic material, atherosclerosis, ascertained, for instance, by intima-media thickness, and IQ testing in children - scores from which are emerging as potentially important predictors of adult health outcomes up to six decades later.
\end{abstract}

Key words

- Birth cohort

- Chronic disease

- Developing country

- Epidemiology

- Life-course
In an overview published in this issue (1), we briefly describe the significant and growing contribution of birth cohorts from highincome countries (of which there are many) to understanding chronic disease aetiology; outline the reasons why birth cohorts from lowand middle-income countries (LMIC, of which there are few) may yield different findings to those apparent in samples drawn from highincome societies, and the consequent need for the maintenance of such studies and the initiation of new ones; provide an audit of birth cohorts from LMIC, and finally, advance future directions in this sphere of research. More than any other LMIC, Brazil has a growing reputation, built on a 30-year research tradition, of establishing, maintaining and exploiting birth cohort studies. Other countries considered to be at a similar stage of economic development are, with few exceptions (2), considerably less well represented, or, in the case of east Asia, north Africa, the Middle East, and the former Soviet Union, to our knowledge, do not feature at all (1). 
This research pedigree is highlighted in the present issue of the Brazilian Journal of Medical and Biological Research, which contains a series of twelve papers from the Ribeirão Preto and São Luís birth cohort studies from the Southeast and Northeast of Brazil, respectively. This contrast of geographical location is important: in keeping with many other countries (3), a North-South divide in socioeconomic circumstances and, therefore health, exists in Brazil. The topics covered in this raft of reports vary and include predictors of perinatal health and maternal risk factors (4-7); early life determinants of cardiovascular risk factors (e.g., dyslipidemia) in childhood and adolescence (8-11); use of health services (12), and a description of dietary characteristics of young adults (13), amongst other topics (14). There is also a guide to the background, objectives, sampling, and methodologies employed across these studies (15), which, together with similar pieces published in past issues of the Brazilian Journal (16), serve as a very useful starting point, particularly for potential collaborators. Some papers herein cover particularly topical issues which include individual- and group-level influences on selected risk factors for chronic disease $(5,6)$ and, inevitably, but very importantly given the forecast of rapid nutritional (epidemiological) transition in Brazil and other LMIC (17), determinants of childhood and early adult obesity $(8,9,11)$.

As indicated by the authors (18), one of the principal objectives of these cohorts is the investigation of life course influences on chronic disease. Given that such conditions, at least in their somatic form, only begin to emerge with sufficient prevalence to enable epidemiological investigation in middle-age, it will be many decades before even the longest running of the studies (Ribeirão Preto, established in 1978/79) yields such insights (assuming it continues to be maintained). However, a number of potentially important uses of existing data remain, many of which are actively being pursued by Barbieri and colleagues and feature in this issue, have been published elsewhere, or are on their agenda (15).

First, as indicated, while chronic somatic diseases are rare in these cohorts given their immaturity, psychiatric illnesses (e.g., depression, generalized anxiety disorder, post-traumatic stress disorder, attention deficit hyperactivity disorder) are presumably not uncommon and, if measured, their aetiology, which may begin in early life $(19,20)$, can be examined. The public health significance of this area of research is potentially considerable: by 2020 it is estimated that clinical depression, for instance, will become the number one cause of disability-adjusted life years in LMIC (21). Second, in what has been termed "the causes of the causes" (22), early life predictors (e.g., foetal growth, post-natal growth, social circumstances) of established (and potentially emerging) risk factors for cardiovascular disease and selected cancers such as raised blood pressure, dyslipidemia, obesity, body composition, cardiorespiratory fitness, physical inactivity, dietary characteristics, smoking, coagulation indices, and inflammatory markers, have been reasonably well examined in developed countries. What is needed now are tests of the same relations in LMIC. Third, an intriguing new hypothesis has linked dehydration in early life (precipitated most commonly by diarrhoea) with later raised blood pressure (23), an established risk factor for stroke and coronary heart disease. While there has been some empirical support for a childhood diarrhoea-blood pressure association $(23,24)$, it is not universal (25). This association, if replicated in studies from LMIC, has particular public health relevance as diarrhoeal illness is more common (23). A higher prevalence of this exposure will also lead to improved precision in studies correlating diarrhoea with blood pressure.

In the fervent hope that further follow-up of these cohorts will take place - we provide our own justification for cohort maintenance 
and extension in this issue (1) - future data collection could include: genetic material (in keeping with birth cohorts from affluent societies (26) and LMIC (27,28)); atherosclerosis, ascertained, for instance, by intima-media thickness, and IQ testing - scores from which are emerging as important predictors of adult health outcomes (29-31) (studies of IQ-risk factors may provide clues as to the mediating pathways (32)).

The clear need for a broader worldwide representation of birth cohort studies would be hastened by a greater international collaboration in the sharing of ideas, fieldwork experience, cross-nation cohort comparisons, and data, in order to carry out the best science in the most productive manner (1). This requires the involvement of a central overseeing agency - such as the World Health Organization - that has the trust of all countries and the resources to develop strategic plans for 'global' life-course epidemiology.

\section{Acknowledgments}

I am grateful to Naomi Hemy for bibliographical assistance. Part of this manuscript was written while David Batty was a visiting fellow at Instituto Materno Infantil Prof. Fernando Figueira, Recife, PE, Brazil.

\section{References}

1. Batty GD, Alves JG, Correia J, Lawlor DA. Examining life-course influences on chronic disease: the importance of birth cohort studies from low- and middle-income countries. Braz $J$ Med Biol Res 2007; 40: 1277-1286.

2. Martorell R, Habicht JP, Rivera JA. History and design of the INCAP longitudinal study (1969-77) and its follow-up (1988-89). J Nutr 1995; 125: 1027S-1041S.

3. McCarron P, Lawlor DA. Editorial comment - North, south: changing directions in cardiovascular epidemiology. Stroke 2003; 34: 26092611.

4. Silva LM, Silva RA, Silva AAM, Bettiol H, Barbieri MA. Racial inequalities and perinatal health in the southeast region of Brazil. Braz J Med Biol Res 2007; 40: 1187-1194.

5. Ribeiro VS, Figueiredo FP, Silva AAM, Bettiol H, Batista RFL, Coimbra LC, et al. Why are the rates of cesarean section in Brazil higher in more developed cities than in less developed ones? Braz $J$ Med Biol Res 2007; 40: 1211-1220.

6. Ribeiro VS, Figueiredo FP, Silva AAM, Batista RLF, Barbieri MA, Lamy Filho $F$, et al. Do socioeconomic factors explain why maternal smoking during pregnancy is more frequent in a more developed city of Brazil? Braz J Med Biol Res 2007; 40: 1203-1210.

7. Lamy Filho F, Assunção Júnior AN, Silva AAM, Lamy ZC, Barbieri $\mathrm{MA}$, Bettiol $\mathrm{H}$. Social inequality and perinatal health: comparison of three Brazilian cohorts. Braz J Med Biol Res 2007; 40: 1177-1186.

8. Bettiol H, Sabbag Filho D, Haeffner LSB, Barbieri MA, Silva AAM, Portela $A$, et al. Do intrauterine growth restriction and overweight at primary school age increase the risk of elevated body mass index in young adults? Braz J Med Biol Res 2007; 40: 1237-1243.

9. Goldani MZ, Haeffner LSB, Agranonik M, Barbieri MA, Bettiol H, Silva AAM. Do early life factors influence body mass index in adolescents? Braz J Med Biol Res 2007; 40: 1231-1236.

10. Figueiredo FP, Silva AAM, Bettiol H, Barbieri MA, Batista RFL, Lamy Filho $\mathrm{F}$, et al. Early life, current socioeconomic position and serum lipids in young adulthood of participants in a cohort study initiated in 1978/1979. Braz J Med Biol Res 2007; 40: 1267-1276.
11. Tomé FS, Cardoso VC, Barbieri MA, Silva AAM, Simões VMF, Garcia $C A$, et al. Are birth weight and maternal smoking during pregnancy associated with malnutrition and excess weight among school age children? Braz J Med Biol Res 2007; 40: 1221-1230.

12. Coimbra LC, Figueiredo FP, Silva AAM, Barbieri MA, Bettiol H, Caldas AJM, et al. Inadequate utilization of prenatal care in two Brazilian birth cohorts. Braz J Med Biol Res 2007; 40: 1195-1202.

13. Molina MC, Bettiol H, Barbieri MA, Silva AAM, Conceição SIO, DosSantos JE. Food consumption by young adults living in Ribeirão Preto, SP, 2002/2004. Braz J Med Biol Res 2007; 40: 1257-1266.

14. Oliveira ZAR, Bettiol $H$, Gutierrez MRP, Silva AAM, Barbieri MA. Factors associated with infant and adolescent mortality. Braz $J$ Med Biol Res 2007; 40: 1245-1255.

15. Cardoso VC, Simões VMF, Barbieri MA, Silva AAM, Bettiol H, Alves MTSSB, et al. Profile of three Brazilian birth cohort studies in Ribeirão Preto, SP and São Luís, MA. Braz J Med Biol Res 2007; 40: 1165-1176.

16. Barbieri MA, Bettiol H, Silva AA, Cardoso VC, Simões VM, Gutierrez MR, et al. Health in early adulthood: the contribution of the 1978/79 Ribeirão Preto birth cohort. Braz J Med Biol Res 2006; 39: 10411055.

17. Yusuf S, Reddy S, Ounpuu S, Anand S. Global burden of cardiovascular diseases: part I: general considerations, the epidemiologic transition, risk factors, and impact of urbanization. Circulation 2001; 104: 2746-2753.

18. Barbieri MA, Bettiol H, Silva AAM, Goldani MZ. Presentation. Braz J Med Biol Res 2007; 40: 1163.

19. Factor-Litvak $P$, Susser $E$. A life course approach to neuropsychiatric outcomes. In: Kuh D, Ben-Shlomo Y (Editors), A life course approach to chronic disease epidemiology. Oxford: Oxford University Press; 2004. p 324-342.

20. Gunnell D, Rasmussen F, Fouskakis D, Tynelius P, Harrison G. Patterns of fetal and childhood growth and the development of psychosis in young males: a cohort study. Am J Epidemiol 2003; 158: $291-300$. 
21. Murray CJL, Lopez AD. The global burden of disease. Boston: WHO, Harvard School of Public Health, World Bank; 1996.

22. Marmot M. Social determinants of health inequalities. Lancet 2005; 365: 1099-1104.

23. Davey Smith G, Leary S, Ness S. Could dehydration in infancy lead to high blood pressure? J Epidemiol Community Health 2006; 60: 142-143.

24. Lawlor DA, Davey Smith G, Mitchell R, Ebrahim S. Adult blood pressure and climate conditions in infancy: a test of the hypothesis that dehydration in infancy is associated with higher adult blood pressure. Am J Epidemiol 2006; 163: 608-614.

25. Batty GD, Davey Smith G, Fall CHD, Aihie Sayer A, Dennison E, Cooper $\mathrm{C}$, et al. Association of diarrhoea in childhood with blood pressure and coronary heart disease in older age: analyses of two UK cohort studies. Int $J$ Epidemiol (in press).

26. Power C, Elliott J. Cohort profile: 1958 British birth cohort (National
Child Development Study). Int J Epidemiol 2006; 35: 34-41.

27. Victora CG, Barros FC. Cohort profile: the 1982 Pelotas (Brazil) birth cohort study. Int J Epidemiol 2006; 35: 237-242.

28. Richter L, Norris S, Pettifor J, Yach D, Cameron N. Cohort profile: Mandela's children: The 1990 birth to twenty study in South Africa. Int J Epidemiol 2007; 36: 504-511.

29. Deary IJ, Batty GD. Cognitive epidemiology. J Epidemiol Community Health 2007; 61: 378-384.

30. Deary IJ, Batty GD. Commentary: pre-morbid IQ and later health the rapidly evolving field of cognitive epidemiology. Int $J$ Epidemiol 2006; 35: 670-672.

31. Batty GD, Deary IJ. Early life intelligence and adult health. BMJ 2004; 329: 585-586.

32. Batty GD, Deary IJ, Gottfredson LS. Premorbid (early life) IQ and later mortality risk: systematic review. Ann Epidemiol 2007; 17: 278288. 